\title{
Pubertal Status Predicts Back Pain, Overtiredness, and Dizziness in American and Dutch Adolescents
}

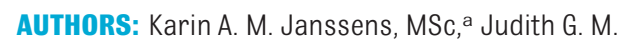
Rosmalen, PhD, a Johan Ormel, PhD, a Frank C. Verhulst, PhD, b Joke A. M. Hunfeld, PhD, ${ }^{c}$ Lloyd A. Mancl, PhD, ${ }^{d}$ Albertine J. Oldehinkel, PhD, a and Linda LeResche, ScDe

aInterdisciplinary Center for Psychiatric Epidemiology, University Medical Center Groningen, University of Groningen, Groningen, Netherlands; Departments of ${ }^{b}$ Child and Adolescent Psychiatry and 'Medical Psychology and Psychotherapy, Erasmus Medical Center, Sophia Children's Hospital, Rotterdam, Netherlands; and Departments of ${ }^{d}$ Dental Public Health Sciences and ${ }^{e}$ Oral Medicine, University of Washington, Seattle, Washington

\section{KEY WORDS}

functional somatic symptoms, pain, pubertal development, gender differences

\section{ABBREVIATIONS}

FSS-functional somatic symptoms

TRAILS—Tracking Adolescents' Individual Lives Survey

www.pediatrics.org/cgi/doi/10.1542/peds.2010-2364

doi:10.1542/peds.2010-2364

Accepted for publication May 5, 2011

Address correspondence to Karin A. M. Janssens, MSc, Interdisciplinary Center for Psychiatric Epidemiology, CC 72, University Medical Center Groningen, P0 Box 30001, 9700 RB, Groningen, Netherlands. E-mail: k.a.m.janssens@med.umcg.nl PEDIATRICS (ISSN Numbers: Print, 0031-4005; Online, 1098-4275). Copyright (C) 2011 by the American Academy of Pediatrics

FINANCIAL DISCLOSURE: The authors have indicated they have no personal financial relationships relevant to this article to disclose.

Funded by the National Institutes of Health (NIH).

\section{WHAT'S KNOWN ON THIS SUBJECT: Functional somatic}

symptoms, such as overtiredness and pain, are more common in girls than in boys, and this difference tends to increase during adolescence. Whether this increase in gender difference can be explained by pubertal development is unclear.

WHAT THIS STUDY ADDS: Two large cohort studies in the Netherlands and the United States revealed no significant gender differences in the association between pubertal development and functional somatic symptoms. Pubertal stage at baseline positively predicted back pain, overtiredness, and dizziness at follow-up.
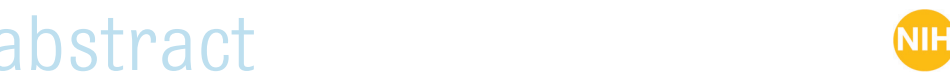

OBJECTIVE: Functional somatic symptoms, symptoms for which no organic pathologic basis can be found, are more prevalent in girls than in boys, and this difference tends to increase during adolescence. This might be explained, at least in part, by pubertal development. We hypothesized that pubertal maturation predicts the development of most functional somatic symptoms and that this especially is true for girls.

METHOD: We used 2 longitudinal population-based studies to examine our hypotheses: the Longitudinal Study of Pain in Adolescents in Seattle ( $n=1996$ [49.7\% girls]) and the Dutch Tracking Adolescents' Individual Lives Survey ( $n=2230$ [51.0\% girls]). Two assessment waves of each study were used. American adolescents were younger than Dutch adolescents at the first (11.6 vs 13.6) and second (14.5 vs 16.2) assessment waves, but they were in about the same pubertal development stage. Functional somatic symptoms were measured by pain questions, the Symptom Checklist-90, and the Youth Self-report. The Pubertal Development Scale was used to assess pubertal development on a continuous scale in both cohorts.

RESULTS: Ordinal logistic regression analyses revealed that American and Dutch adolescents at a later pubertal status at baseline were more likely (odds ratios ranged from 1.24 to 1.61 ) to report back pain, overtiredness, and dizziness but not stomach pain and headache 2 to 3 years later. Although these relationships were not equally strong for boys and girls, no significant gender differences were found.

CONCLUSIONS: Pubertal status predicted the frequency of some, but not all, functional somatic symptoms at follow-up. Pediatrics 2011;128: $553-559$ 
Functional somatic symptoms (FSS), symptoms for which no organic pathologic basis can be found, are common in adolescents worldwide.1,2 These symptoms can have a significant impact on adolescents' lives, by causing school-related problems, problems with peers, and problems in the family. In general, girls experience more FSS than boys, and this difference increases during adolescence. ${ }^{4}$ It is unknown which factors are responsible for this increase in gender difference. One possibility is that pubertal development plays a role. Cross-sectional studies suggest that the association between pubertal development and FSS is different in boys and girls. ${ }^{4-6}$ However, research in this field is scarce, and findings are sometimes contradictory. Most studies show that musculoskeletal symptoms, headache, dizziness, and fatigue increase during pubertal development in girls. ${ }^{4-6}$ Findings on the relationship between gastrointestinal symptoms and pubertal development in girls are less consistent because some studies found a negative association, some found a positive association, and some did not find a significant association between the two. ${ }^{4-7}$ In boys, pubertal development generally is associated with a larger decrease in gastrointestinal symptoms and with a smaller increase in musculoskeletal symptoms, headache, dizziness, and fatigue than in girls, resulting in a lower overall prevalence of FSS in boys than in girls at the completion of pubertal development. ${ }^{4-6}$

The relationship between specific FSS and pubertal development has, to the best of our knowledge, only been studied Iongitudinally for headache and stomach pain. ${ }^{7,8} \mathrm{As}$ a consequence, it is unknown whether other FSS increase or decrease as adolescents proceed through pubertal development and whether this depends on gender. We hypothesized that (1) pubertal maturation is a risk factor for development of back pain, headache, dizziness, and overtiredness but not for gastrointestinal symptoms and (2) the relationship between pubertal maturation and specific somatic symptoms is stronger in girls than in boys. To enlarge the robustness of our findings, we studied these hypotheses with Iongitudinal data from 2 samples, 1 consisting of Dutch and 1 of American adolescents.

\section{METHODS}

\section{The Tracking Adolescents' Individual Lives Survey}

The Tracking Adolescents' Individual Lives Survey (TRAILS) is a prospective cohort study of Dutch adolescents. The data reported here come from the second and third assessment waves of the TRAILS, which ran from September 2003 to December 2004 and from September 2005 to August 2008, respectively. The questionnaires used in the current study were all filled out by the adolescents at school under the supervision of a TRAILS employee.

TRAILS participants were selected from 5 municipalities in the north of the Netherlands, including both urban and rural areas. All children born between October 1, 1989, and September 30, 1990 (first 2 municipalities), or between October 1, 1990, and September 30, 1991 (last 3 municipalities), were eligible for inclusion, provided that their schools were willing to cooperate and that they were able to participate in the study. More than $90 \%$ of the schools, accommodating 3145 children, agreed to participate in the study. A small proportion (6.7\%) of these children was excluded because of mental or physical incapability or language problems. Of the remaining 2935 children, $76.0 \%$ ( $n=2230[50.8 \%$ girls]; mean age: 11.1 years; SD: 0.6; range: 10-12) were enrolled in the study. Information about the sample selection and differences between responders and nonresponders at baseline have been described elsewhere. ${ }^{9}$ A total of $10 \%$ of the sample had at least 1 parent born in a nonWestern country.

Of 2230 baseline participants, $96.4 \%$ ( $n=2149$ [51.0\% girls]; mean age: 13.7 years; SD: 0.5; range: 12-15) participated in the first follow-up assessment (T2), which was 2 to 3 years after assessment wave 1 ( $\mathrm{T} 1)$. At the third assessment wave (T3), which was 2 to 3 years after T2, the response was $81.4 \%$ ( $n=1816$ [53.3\% girls]; mean age: 16.3; SD: 0.7; range: 15-18). Attrition at the second assessment was not associated with psychopathology. ${ }^{10}$ Because the instruments used at T2 and $\mathrm{T} 3$ were most comparable with the instruments used in Seattle, Washington, data from these waves were used in the current study. The study was approved by the Dutch Central Committee on Research Involving Human Subjects. Parents' and adolescents' written informed consent was obtained.

\section{The Longitudinal Study of Pain in Adolescents in Seattle}

The Longitudinal Study of Pain in Adolescents in Seattle is a longitudinal cohort study in American adolescents. Subjects in this cohort study were boys and girls, initially all aged 11 years, who were randomly selected from the enrollees of Group Health, a large nonprofit integrated health care system in Washington state. The study included a baseline interview (which ran from May 2000 to April 2001) and a 3-year follow-up interview (which ran from April 2003 to March 2004), each conducted by telephone. Both interviews were used for the current study. Children not sufficiently proficient in English to understand the interview questions or those whose parents were not sufficiently proficient in Eng- 
lish to provide informed consent were considered ineligible.

Of all adolescents invited for this study 49\% ( $n=1996$ [49.7\% girls]; mean age: 11.6; SD: 0.3; range: 11.0-12.1) participated at baseline. Information about sample selection and differences between responders and nonresponders at baseline can be found elsewhere. ${ }^{4}$ The majority of adolescents $(66.5 \%)$ described their race as white. At the 3-year telephone follow-up interview $91.0 \%$ of the adolescents ( $n=1817$ [49.4\% girls]; mean age: 14.5; SD: 0.3) participated again. All procedures were approved by the institutional review boards of Group Health and the University of Washington. Both the parent or legal guardian and the child provided informed consent (adults) or assent (children).

\section{Functional Somatic Symptoms}

Both studies assessed back pain, stomach pain, and headache, the most prevalent types of pain in adolescents. The adolescents were asked how often they had experienced these symptoms during the past 3 months. In the Netherlands, adolescents filled out questionnaires with 7 response categories: "not at all;" "less than once a month;" "once a month;" "two to three times a month;" "once a week;" "two to six times a week;" and "almost every day." In the United States, adolescents could answer the interviewer with 4 response categories: "not at all;" "fewer than half of the days;" "more than half of the days;" and "almost every day." There were few adolescents who reported having pain almost every day in either the Dutch or American sample. Therefore, in the Dutch sample, this category was combined with the category "Two to six times a week" and in the American sample with "More than half of the days," resulting in 6 response categories in the Dutch and 3 in the American sample. In the United
States, subjects were explicitly asked to report pains that lasted a whole day or more or pains that they experienced several times in a year and not to report little aches and pains that did not last very long. In the Netherlands, no such restrictions were made.

In the Dutch study, FSS other than pain symptoms were assessed with the Youth Self-report, ${ }^{11}$ and in the American study, they were assessed during the telephone interview with the Symptom Checklist-90. ${ }^{2}$ We used only items of both questionnaires that we considered comparable. These items were overtiredness and dizziness without obvious reason from the Youth Selfreport, which could be rated on a 3-point scale ("not at all," "sometimes/a little bit," or "often/a lot'), and feeling low in energy or slowed down and faintness or dizziness from the Symptom Checklist, which could be rated on a 5-point scale ("not at all," "a little bit," "moderately," "quite a bit," or "extremely"). The categories "quite a bit" and "extremely" were combined because few adolescents reported experiencing these symptoms extremely. The time frame of the Youth Self-report was 6 months, whereas that of the Symptom Checklist was 1 month.

\section{Pubertal Development}

In both studies, the Pubertal Development Scale, which is known to be a reliable instrument, 13,14 was used to measure pubertal development. The Pubertal Development Scale assesses development on 5 characteristics for each gender. These characteristics include growth spurt in height, skin changes and body hair for both boys and girls, breast development and menarche in girls, and voice change and facial-hair growth in boys. Subjects were asked to respond on a selfreport questionnaire (Dutch) or in a telephone interview (American) to each item on a 4-point ordinal scale (no development $=1$, development barely begun $=2$, development definitely underway $=3$, and development already completed $=4$ ). The menarche item was scored as 1 if premenarche and 4 if menstrual periods had begun. The mean item score of the 5 items was calculated and used as a continuous measure to increase the power to detect an effect. ${ }^{15}$

\section{Statistical Analyses}

We performed ordinal logistic regression analyses to test our hypotheses. This analysis method is an extension of binary logistic regression and is appropriate when the outcome variable contains more than 2 ordinal categories. An important assumption to perform these analyses is the proportional odds assumption. Violations of this assumption were tested by performing Brant tests. ${ }^{16}$ By performing ordinal logistic regression analyses, we examined whether pubertal status at the baseline of this study (ie, at baseline in the American sample and at T2 in the Dutch sample) predicted a specific FSS at follow-up (ie, at 3-year follow-up in the American sample and at $\mathrm{T3}$, which was 2 to 3 years after T2, in the Dutch sample). The analyses were adjusted for gender because, in general, girls have more FSS ${ }^{1,2}$ and are further along in pubertal development than boys at a given age. ${ }^{17}$ We performed all analyses again, adjusting for age, to rule out that age, rather than pubertal status itself, predicted the relationship between pubertal status and FSS. To examine whether pubertal status truly predicted the direction of development of FSS, we performed the same analyses adjusting for the corresponding symptom at the first time point.

To test our second hypothesis that significant gender differences exist, an interaction term of gender and pubertal status at baseline was computed. We 
TABLE 1 Descriptive Statistics of the Dutch and American Girls and Boys at Baseline and Follow-up 2 to 3 Years Later

\begin{tabular}{|c|c|c|c|c|c|c|c|c|}
\hline & \multicolumn{2}{|r|}{ Americans at Baseline } & \multicolumn{2}{|r|}{ Dutch at Baseline } & \multicolumn{2}{|c|}{ Americans at Follow-up } & \multicolumn{2}{|r|}{ Dutch at Follow-up } \\
\hline & $\begin{array}{c}\text { Valid } \\
n\end{array}$ & Mean (SD) or \% & $\begin{array}{c}\text { Valid } \\
n\end{array}$ & Mean (SD) or \% & $\begin{array}{c}\text { Valid } \\
n\end{array}$ & Mean (SD) or \% & $\begin{array}{c}\text { Valid } \\
n\end{array}$ & Mean (SD) or \% \\
\hline \multicolumn{9}{|l|}{ Girls } \\
\hline Age, y & 992 & $11.6(0.3)$ & 1069 & $13.6(0.5)$ & 897 & $14.5(0.3)$ & 952 & $16.3(0.7)$ \\
\hline Pubertal status & 911 & 2.3 (0.6); range: $1.0-4.0$ & 1001 & 2.7 (0.7); range: $1.0-4.0$ & 880 & 3.5 (0.5); range: $1.6-4.0$ & 866 & 3.3 (0.4); range: $1.2-4.0$ \\
\hline $\mathrm{BMI}, \mathrm{kg} / \mathrm{m}^{2}$ & 904 & $19.6(3.9)$ & 1028 & $19.3(3.3)$ & 888 & $22.0(4.2)$ & 834 & $21.7(3.2)$ \\
\hline Headache & 989 & $19.2^{\mathrm{a}, \mathrm{b}}$ & 1069 & $56.7^{a, b}$ & 897 & $21.4^{a, b}$ & 871 & $51.6^{a, b}$ \\
\hline Stomach pain & 991 & $27.8^{\mathrm{a}, \mathrm{b}}$ & 1068 & $46.9^{a, b}$ & 897 & $16.7^{\mathrm{a}, \mathrm{b}}$ & 875 & $35.9^{a, b}$ \\
\hline Back pain & 989 & $15.0^{\mathrm{a}, \mathrm{b}}$ & 1068 & $30.5^{a, b}$ & 896 & $25.2^{a, b}$ & 874 & $35.6^{a, b}$ \\
\hline Dizziness & 992 & $33.3^{\mathrm{a}, \mathrm{c}}$ & 1072 & $40.9^{a, d}$ & 897 & $33.9^{\mathrm{a}, \mathrm{c}}$ & 880 & $42.6^{a, d}$ \\
\hline Overtiredness or lack of energy & 991 & $57.3^{\mathrm{a}, \mathrm{c}}$ & 1070 & $43.1^{\mathrm{a}, \mathrm{d}}$ & 897 & $55.5^{\mathrm{a}, \mathrm{c}}$ & 880 & $54.2^{\mathrm{a}, \mathrm{d}}$ \\
\hline \multicolumn{9}{|l|}{ Boys } \\
\hline Age, y & 1004 & $11.6(0.3)$ & 1018 & $13.6(0.5)$ & 920 & $14.5(0.3)$ & 867 & $16.3(0.7)$ \\
\hline Pubertal status & 970 & 1.9 (0.4) range: $1.0-3.6$ & 1006 & 2.1 (0.6) range: $1.0-4.0$ & 915 & 2.7 (0.5) range: $1.0-4.0$ & 768 & 3.0 (0.5) range: $1.0-4.0$ \\
\hline $\mathrm{BMl}, \mathrm{kg} / \mathrm{m}^{2}$ & 951 & $19.9(4.3)$ & 1000 & $18.7(3.1)$ & 914 & $22.3(4.5)$ & 759 & $20.9(3.4)$ \\
\hline Headache & 1002 & $16.7^{\mathrm{a}, \mathrm{b}}$ & 1013 & $44.5^{\mathrm{a}, \mathrm{b}}$ & 920 & $13.5^{\mathrm{a}, \mathrm{b}}$ & 769 & $34.9^{a, b}$ \\
\hline Stomach pain & 1002 & $22.0^{\mathrm{a}, \mathrm{b}}$ & 1015 & $37.4^{a, b}$ & 920 & $12.1^{\mathrm{a}, \mathrm{b}}$ & 771 & $19.9^{a, b}$ \\
\hline Back pain & 998 & $11.1^{\mathrm{a}, \mathrm{b}}$ & 1015 & $22.1^{\mathrm{a}, \mathrm{b}}$ & 919 & $16.9^{a, b}$ & 769 & $27.4^{\mathrm{a}, \mathrm{b}}$ \\
\hline Dizziness & 1002 & $32.0^{\mathrm{a}, \mathrm{c}}$ & 1019 & $24.5^{\mathrm{a}, \mathrm{d}}$ & 919 & $25.7^{\mathrm{a}, \mathrm{c}}$ & 772 & $22.0^{\mathrm{a}, \mathrm{d}}$ \\
\hline Overtiredness or lack of energy & 1002 & $58.6^{\mathrm{a}, \mathrm{c}}$ & 1016 & $29.0^{\mathrm{a}, \mathrm{d}}$ & 919 & $47.6^{\mathrm{a}, \mathrm{c}}$ & 772 & $29.5^{\mathrm{a}, \mathrm{d}}$ \\
\hline
\end{tabular}

a Percentage of girls and boys who experienced this symptom at least once during the ${ }^{b}$ past 3 months, the ${ }^{c}$ past month, or the ${ }^{d}$ past 6 months.

examined whether this interaction term, adjusted for the main effects of gender and pubertal status at baseline, predicted a specific FSS at followup. A result was considered statistically significant when the $95 \%$ confidence interval of the odds ratio did not include 1. Stata version 10 (Stata Corp, College Station, TX) was used to perform all analyses.

\section{RESULTS}

\section{Descriptive Statistics}

The Dutch boys and girls were older than the Americans, but the samples were fairly comparable with regard to mean pubertal development score (Table 1). Adolescents from both co- horts were, on average, already in a mid-pubertal development stage at baseline. That American adolescents start their pubertal development earlier than European adolescents is in line with previous research. 18,19 Furthermore, American adolescents had slightly higher BMI scores than Dutch adolescents, in keeping with known national differences. ${ }^{19,20}$ Dutch adolescents reported having experienced pain more often than American adolescents.

\section{Pubertal Status as a Predictor of FSS at Follow-up}

As is shown in Table 2, the higher the pubertal status of adolescents at baseline, the more likely they were to re- port back pain, overtiredness, and dizziness but not stomach pain and headache at follow-up 2 to 3 years later. After adjusting for age, results were essentially the same. When we adjusted for the corresponding baseline FSS, results pointed in the same direction and remained statistically significant except for the relationship between pubertal development and dizziness in Dutch adolescents. The Brant test did not indicate that the proportional odds assumption was violated for any of the analyses $(P>.05)$.

\section{Gender Differences}

Results of the analyses of the relationships between pubertal status at base-

TABLE 2 Longitudinal Relationship Between Pubertal Development at Baseline and FSS at Follow-up 2 to 3 Years Later Analyzed With Ordinal Logistic Regression Analyses

\begin{tabular}{|c|c|c|c|c|c|}
\hline & $\begin{array}{l}\text { Headache at } \\
\text { Follow-up }\end{array}$ & $\begin{array}{l}\text { Stomach Pain at } \\
\text { Follow-up }\end{array}$ & $\begin{array}{l}\text { Back Pain at } \\
\text { Follow-up }\end{array}$ & $\begin{array}{l}\text { Overtiredness or } \\
\text { Lack of Energy at } \\
\text { Follow-up }\end{array}$ & $\begin{array}{l}\text { Dizziness at } \\
\text { Follow-up }\end{array}$ \\
\hline \multirow[t]{2}{*}{ American adolescents, pubertal status at baseline } & $1.18(0.94-1.48)^{a}$ & $1.26(0.98-1.62)^{a}$ & $1.61(1.30-1.99)^{a, c}$ & $1.33(1.12-1.58)^{a, c}$ & $1.35(1.11-1.64)^{\mathrm{a}, \mathrm{c}}$ \\
\hline & $1.11(0.87-1.41)^{\mathrm{b}}$ & $1.25(0.97-1.61)^{\mathrm{b}}$ & $1.52(1.22-1.89)^{\mathrm{b}, \mathrm{c}}$ & $1.25(1.05-1.49)^{\mathrm{b}, \mathrm{c}}$ & $1.26(1.03-1.53)^{\mathrm{b}, \mathrm{c}}$ \\
\hline \multirow[t]{2}{*}{ Dutch adolescents, pubertal status at baseline } & $1.07(0.93-1.25)^{\mathrm{a}}$ & $0.88(0.75-1.04)^{a}$ & $1.34(1.13-1.57)^{\mathrm{a}, \mathrm{c}}$ & $1.30(1.11-1.51)^{\mathrm{a}, \mathrm{c}}$ & $1.24(1.05-1.46)^{a, c}$ \\
\hline & $1.07(0.92-1.25)^{\mathrm{b}}$ & $0.91(0.76-1.08)^{b}$ & $1.24(1.04-1.46)^{\mathrm{b}, \mathrm{c}}$ & $1.26(1.08-1.48)^{\mathrm{b}, \mathrm{c}}$ & $1.16(0.98-1.37)^{b}$ \\
\hline
\end{tabular}

Data are odds ratio ( $95 \%$ confidence interval).

a Adjusted for gender.

b Adjusted for gender and the corresponding baseline FSS.

c Significant effect. 
line and specific FSS at follow-up stratified by gender pointed mostly in the same direction for each gender (Table 3). Although relationships generally were in the same direction for boys and girls, the results were not always equally strong for each gender and sometimes failed to reach significance in boys (Table 3). The interaction effects, however, indicated that these gender differences were not statistically significant (all $P$ values $>0.18$ ) (Table 3).

\section{Growth Spurt and Back Pain}

Because pubertal status at baseline was only significantly related to back pain and not to headache and stomach pain, we wondered whether this association could be explained by a growth spurt. We therefore examined whether growth spurt (ie, the specific item from the Pubertal Development Scale) at baseline predicted back pain at follow-up. Growth spurt at baseline was not a significant predictor of back pain at follow-up in the American sample (odds ratio: 1.04 [95\% confidence interval: $0.89-1.21]$ ) or in the Dutch sample (odds ratio: 1.13 [95\% confidence interval: 0.98-1.31]).

\section{DISCUSSION}

This study indicates that Dutch and American adolescents who are in a later pubertal stage at baseline report more back pain, overtiredness, and dizziness but not more stomach pain or headache 2 to 3 years later. We did not find any significant gender difference in the longitudinal relationship between pubertal development and FSS.

A strength of our research is that we used 2 large population-based studies, 1 of American and 1 of Dutch adolescents. This enhances the generalizability of our findings because most of the findings were comparable in both studies despite racial and age differences. Furthermore, the use of 2 samples enhanced the robustness of our findings because different instruments (eg, different questionnaires with different response categories) were used in the 2 studies. Despite these methodological differences, results were fairly similar in both samples. Another advantage is that we had longitudinal data available, which allowed us to examine whether pubertal status, rather than age, was predictive of FSS at follow-up.

We have to acknowledge 2 limitations to our study. First, adolescents already were, on average, in a mid-pubertal development stage at the beginning of our studies. Therefore, we might have missed some effects of early pubertal development. Another possible shortcoming is that we are not sure if the FSS measured were a result of conventional medical conditions. In the Youth Self-report, it was stated that the symptoms had to occur without obvious cause, but in the other questionnaires used to assess FSS, no such re- strictions were made. However, medical conditions are seldom found in adolescents with common somatic complaints. ${ }^{21,22}$ Moreover, findings in the 2 cohorts were largely comparable, and the prevalence of symptoms attributed to medical conditions is likely to be different in the 2 cohorts because the Dutch adolescents were asked only to report symptoms without obvious cause. Therefore, medical conditions are not likely to have substantially influenced the associations between pubertal status and FSS.

Some differences between the samples have to be noted. Dutch adolescents reported having experienced pain much more often than American adolescents. This difference most likely can be explained by the restrictions made in the American questionnaire not to report minor pains and only to report pains that lasted for 1 day or longer. Furthermore, in Seattle the data were collected by interviews, whereas the Dutch adolescents reported their symptoms on a questionnaire, which in general results in higher rates of symptom report. In addition to mean pain frequency, the response rates, response categories, the duration of the recall period of overtiredness and dizziness, follow-up time intervals, and ethnicity differed between the samples. Despite all these methodological differences, results were essentially the same in each sam-

TABLE 3 Longitudinal Relationship Between Pubertal Development at Baseline and FSS at Follow-up 2 to 3 Years Later, Stratified According to Gender

\begin{tabular}{|c|c|c|c|c|c|}
\hline & $\begin{array}{l}\text { Headache at } \\
\text { Follow-up }\end{array}$ & $\begin{array}{l}\text { Stomach Pain } \\
\text { at Follow-up }\end{array}$ & $\begin{array}{l}\text { Back Pain at } \\
\text { Follow-up }\end{array}$ & $\begin{array}{c}\text { Overtiredness or } \\
\text { Lack of Energy at } \\
\text { Follow-up }\end{array}$ & $\begin{array}{l}\text { Dizziness at } \\
\text { Follow-up }\end{array}$ \\
\hline American girls, pubertal status at baseline & $1.24(0.94-1.61)$ & $1.27(0.94-1.72)$ & $1.50(1.16-1.93)^{\mathrm{b}}$ & $1.44(1.16-1.78)^{\mathrm{b}}$ & $1.29(1.02-1.63)^{\mathrm{b}}$ \\
\hline American boys, pubertal status at baseline & $1.02(0.66-1.59)$ & $1.23(0.78-1.93)$ & $1.90(1.28-2.82)^{\mathrm{b}}$ & $1.15(0.86-1.53)$ & $1.47(1.05-2.06)^{b}$ \\
\hline$P$ value of the interaction effect ${ }^{a}$ & .61 & .90 & .34 & .19 & .55 \\
\hline Dutch girls, pubertal status at baseline & $1.14(0.95-1.37)$ & $0.91(0.74-1.10)$ & $1.31(1.07-1.61)^{\mathrm{b}}$ & $1.29(1.07-1.55)^{b}$ & $1.30(1.06-1.58)^{b}$ \\
\hline Dutch boys, pubertal status at baseline & $0.96(0.75-1.23)$ & $0.83(0.61-1.13)$ & $1.37(1.05-1.79)^{\mathrm{b}}$ & $1.31(1.00-1.70)^{\mathrm{b}}$ & $1.11(0.83-1.49)$ \\
\hline$P$ value of the interaction effect ${ }^{\mathrm{a}}$ & .25 & .85 & .69 & .99 & .39 \\
\hline
\end{tabular}


ple, which suggests that our findings are quite robust.

The Iongitudinal relationships we found between pubertal status and FSS are largely comparable with the cross-sectional associations in our previous studies. ${ }^{4,5}$ In contrast to the Dutch baseline study ${ }^{5}$ and a previous Iongitudinal study by Stanford et al, ${ }^{7}$ the current study did not find that adolescents in a lower pubertal stage report more stomach pain. Both previous studies indicated that lagging behind one's peers in pubertal development is associated with reporting stomach pain. Because most adolescents in the current study already were in a mid-pubertal development stage, the effect of lagging behind one's peers might have been missed. The largest difference with the American cross-sectional study ${ }^{4}$ is that the current study did not reveal a longitudinal positive association between pubertal status and headache in girls. An explanation might be the lack of older adolescents in the current study compared with the cross-sectional study. It might take some time before having reached a mature pubertal status influences the frequency of headache in girls. This might also explain why no cross-sectional association was found between pubertal status and headache in girls in the Dutch baseline study, when participants were, on average, even younger than in the American sample. The explanation also is in line with a previous study by KrönerHerwig et al, ${ }^{8}$ who found that reaching menarche 2 or more years ago was predictive of headache, whereas having reached menarche only 1 year ago was not associated with headache. Al-

\section{REFERENCES}

1. Eminson DM. Medically unexplained symptoms in children and adolescents. Clin Psychol Rev. 2007;27 (7):855-871

2. Perquin CW, Hazebroek-Kampschreur AA, Hunfeld JA, et al. Pain in children and though intuitively plausible, growth spurt did not explain why we found a Iongitudinal association between pubertal development and back pain but not the other pain symptoms. This is in keeping with previous studies that found that mechanical factors, like carrying backpacks and physical activity, did not predict back pain at follow-up..$^{23,24}$

Although observed associations between pubertal development and FSS were not always equally strong for boys and girls, we found no statistically significant gender differences in the Iongitudinal relationship between pubertal status and specific FSS. Therefore, we did not find evidence to support the hypothesis that pubertal development causes girls to experience FSS more frequently than boys during early and mid-adolescence. .5 $^{25}, 2$ Gender differences attributed to pubertal development may become apparent during late adolescence, possibly because the sensitizing effects of the sometimes painful physiologic signals associated with menstruation take some time to develop. ${ }^{27}$ PsychoIogical factors also likely contribute to the increasing difference in the amount of FSS reported by boys and girls during adolescence: growing into adulthood may increase the expectation for boys not to report and thereby decrease the willingness for boys to report FSS. ${ }^{28}$

\section{CONCLUSIONS}

Pubertal status was associated with some, but not all, FSS, suggesting that biological factors are differentially involved in the etiology of various FSS. It is tempting to speculate that back pain, dizziness, and overtiredness predominantly result from a different biological pathway than stomach pain and headache, but this needs to be explored further.

\section{ACKNOWLEDGMENTS}

This research is part of the Longitudinal Study of Pain in Adolescents in Seattle. This study was supported by grant DE08773 from the National Institutes Health (National Institute of Dental and Craniofacial Research). This research is also part of the TRAILS. The TRAILS has been financially supported by various grants from the Netherlands Organization for Scientific Research NWO (Medical Research Council program grant GB-MW 940-38-011; Zon-MW Brainpower grant 100-001004; Zon-Mw Risk Behavior and Dependence grants 60-60600-98-018 and 6060600-97-118; Zon-Mw Culture and Health grant 261-98-710; Social Sciences Council medium-sized investment grants GB-MaGW 480-01-006 and GB-MaGW 480-07-001; Social Sciences Council project grants GB-MaGW 45703-018, GB-MaGW 452-04-314, and GBMaGW 452-06-004; and NW0 large-sized investment grant 175.010.2003.005); the Sophia Foundation for Medical Research (projects 301 and 393), the Dutch Ministry of Justice (WODC), the European Science Foundation (EuroSTRESS project FP-006), and the participating universities that are various departments of the University Medical Center and University of Groningen, the Erasmus University Medical Center Rotterdam, the University of Utrecht, the Radboud Medical Center Nijmegen, and the Parnassia Bavo group, all in the Netherlands. adolescents: a common experience. Pain. 2000;87(1):51-58

3. Eminson DM, Sidney B, Shortall A, Woods T, Faragher B. Physical symptoms and illness attitudes in adolescents: an epidemiologi- cal study. J Child Psychol Psychiatry. 2006; 37 (5):519-528

4. LeResche L, Mancl LA, Drangsholt MT, Saunders K, Korff MV. Relationship of pain and symptoms to pubertal development 
in adolescents. Pain. 2005;118(1-2): 201-209

5. Oldehinkel AJ, Verhuls FC, Ormel J. Mental health problems during puberty: Tannerstage related differences in specific symptoms. The TRAILS study. J Adolesc. 2011; 34(1):73-85

6. Rhee H. Relationships between physical symptoms and pubertal development. J Pediatr Health Care. 2005;19(2):95-103

7. Stanford EA, Chambers CT, Biesanz JC, Chen E. The frequency, trajectories and predictors of adolescent recurrent pain: a population-based approach. Pain. 2008;138(1):11-21

8. Kröner-Herwig B, Vath N. Menarche in girls and headache: a longitudinal analysis. Headache. 2009;49(6):860-867

9. de Winter AF, Oldehinkel AJ, Veenstra R, Brunnekreef JA, Verhulst FC, Ormel J. Nonresponse bias in mental health determinants and outcomes in a large sample of preadolescents. Eur J Epidemiol. 2005; 20(2):173-181

10. Huisman M, Oldehinkel AJ, de Winter A, et al. Cohort profile: the Dutch "TRacking Adolescents' Individual Lives' Survey”; TRAILS. Int J Epidemiol. 2008;37(6):1227-1235

11. Achenbach TM, Dumenci L, Rescorla LA. DSM-oriented and empirically based approaches to constructing scales from the same item pools. J Clin Child Adolesc Psychol. 2003;32(3):328-340

12. Derogatis LR, Cleary PA. Confirmation of the dimensional structure of the SCL-90: a study in construct validation. J Clin Psychol. 1977; $33(4): 981-989$

13. Petersen AC, Crockett L, Tobin-Richard M, Boxer A. A self-report measure of pubertal status: reliability and validity and initial norms. J Youth Adolesc. 1988;17 (2):117-133

14. Bond L, Clements J, Bertalli N, et al. A comparison of self-reported puberty using the Pubertal Development Scale and the Sexual Maturation Scale in a school-based epidemiologic survey. J Adolesc. 2006;29(5): 709-720

15. Streiner DL. Breaking up is hard to do: the heartbreak of dichotomizing continuous data. Can J Psychiatry. 2002;47 (3):262-266

16. Long JS, Freese J. Regression Models for Categorical Outcomes Using Stata. 2nd ed. College Station, TX: Stata Press; 2005

17. de Muinck Keizer-Schrama SM, Mul D. Trends in pubertal development in Europe. Hum Reprod Update. 2001;7 (3):287-291

18. Lee PA, Guo SS, Kulin HE. Age of puberty: data from the United States of America. APMIS. 2001;109(2):81-88

19. Freedman DS, Khan LK, Serdula MK, Ogden $\mathrm{CL}$, Dietz WH. Racial and ethnic differences in secular trends for childhood BMI, weight and height. Obesity. 2006;14(2):301-308

20. de Wilde JA, Van Dommelen P, Middelkoop BJC, Verkerk PH. Trends in overweight and obesity prevalence in Dutch, Turkish, Moroccan and Surinamese South Asian children in the Netherlands. Arch Dis Child. 2009;94(10):795-800
21. Croffie JM, Fitzgerald JF, Chong SK. Recurrent abdominal pain in children-a retrospective study of outcome in a group referred to a pediatric gastroenterology practice. Clin Pediatr (Phila). 2000;39(5): 267-274

22. Goodman JE. The epidemiology of pain in children and adolescents: a review. Pain. 1991;46(3): 247-264

23. Watson KD, Papageorgiou AC, Jones GT, TayIor S, Symmoms DPM, Silman AJ. Low back pain in schoolchildren: the role of mechanical and psychosocial factors. Arch Dis Child. 2003;88(1):12-17

24. Jones GT, Watson KD, Silman AJ, Symmons DPM, Macfarlane GJ. Predictors of low back pain in British schoolchildren: a populationbased prospective cohort study. Pediatrics. 2003;111(4 pt 1):922-828

25. Paller CJ, Campbell CM, Edwards RR, Dobs AS. Sex-based differences in pain perception and treatment. Pain Med. 2009;10(2): 289-299

26. Fillingim RB, King CD, Ribeiro-Dasilva $M C$, Rahim-Williams B, Riley JL. Sex, gender, and pain: A review of recent clinical and experimental findings. J Pain. 2009;10(5):447-485

27. Berkley KJ. Sex differences in pain. Behav Brain Sci. 1997;20(3):371-380

28. Robinson ME, Riley JL, Myers CD, et al. Gender role expectations of pain: relationship to sex differences in pain. J Pain. 2001;2(5): 251-257 